\title{
Lymph Node Morphology in Stage II Colorectal Cancer
}

Annabelle Greenwood. BBMedSc (Hons). Department of Surgery and Anaesthesia, University of Otago, Wellington, New Zealand.

Mr John Keating. MB BS (Hons). Department of General Surgery, Wellington Regional Hospital, Wellington, New Zealand.

Associate Professor Diane Kenwright. MB ChB. Department of Pathology and Molecular Medicine, University of Otago, Wellington, New Zealand.

Mr Ali Shekouh. MD. Department of General Surgery, Wellington Regional Hospital, Wellington, New Zealand.

Mr Alex Dalzell. MD. Department of General Surgery, Wellington Regional Hospital, Wellington, New Zealand.

Associate Professor Elizabeth Dennett. MmedSci, MappMgt. Department of Surgery and Anaesthesia, University of Otago, and Department of General Surgery, Wellington Regional Hospital, Wellington, New Zealand.

Dr Kirsty Danielson. PhD. Department of Surgery and Anaesthesia, University of Otago, Wellington, New Zealand.

Correspondence: Annabelle L Greenwood. Email: grean360@ student.otago.ac.nz.

Disclaimers: All authors declare that there are no conflicts of interest.

Ethics: This study was conducted in accordance with the Declaration of Helsinki and ethical approval was approved by the Health \& Disabilities Ethics Committee, New Zealand

(15/CEN/143; 18/CEN/138).

Patient consent: Written informed consent was obtained from all patients before the study was conducted. 


\begin{abstract}
Background: Colorectal cancer is one of the leading causes of cancer-associated morbidity and mortality worldwide. The local anti-tumour immune response is particularly important for patients with stage II where the tumour-draining lymph nodes have not yet succumbed to tumour spread. The lymph nodes allow for the expansion and release of B cell compartments such as primary follicles and germinal centres. A variation in this anti-tumour immune response may influence the observed clinical heterogeneity in stage II patients.
\end{abstract}

Aim: The aim of this study was to explore tumour-draining lymph node histomorphological changes and tumour pathological risk factors including the immunomodulatory microRNA-21 (miR-21) in a small cohort of stage II CRC.

Methods: A total of 23 stage II colorectal cancer patients were included. Tumour and normal mucosa samples were analysed for miR-21 expression levels and B-cell compartments were quantified from Haematoxylin and Eosin slides of lymph nodes. These measures were compared to clinicopathological risk factors such as perforation, bowel obstruction, T4 stage and high-grade.

Results: We observed greater follicle density in patients with a lower tumour T stage and higher germinal centre density in patients with higher pre-operative carcinoembryonic antigen levels. Trends were also detected between tumours with deficiency in mismatch repair proteins, lymphatic invasion and both the density and size of B-cell compartments. Lastly, elevated tumour miR-21 was associated with decreased follicle and germinal centre size.

Conclusion: Variation in B-cell compartments of tumour-draining lymph nodes is associated with clinicopathological risk factors in stage II CRC patients.

\title{
What does this paper add to the literature?
}

This study demonstrates the variability of tumour draining lymph node morphological features in stage II CRC patients. This provides new scope for biomarker discovery in stage II CRC patients which is a research priority for this patient group. 


\section{INTRODUCTION}

In 2018 colorectal cancer (CRC) was the second leading cause of cancer-associated morbidity and third leading cause of mortality worldwide [1]. While clinical guidelines for treatment decisions are relatively straightforward for most patients, the decision to use adjuvant chemotherapy in patients with stage II disease is complicated [2]. Patients with Stage II CRC have a 5-year survival rate of 60$80 \%$. However, additional survival benefit from adjuvant chemotherapy is only between $0-4 \%$. High-risk clinicopathological features such as perforation, bowel obstruction, T4 stage and high-grade are associated with patients with 'higher-risk' stage II that may benefit from chemotherapy as patients with stage III do [2]. However, the current risk assessment has limited prognostic value where overall survival (OS) for 'low-risk' patients is still between $68-86 \%$ and for 'high-risk' patients between 57 $76 \%[3,4]$. Further, this risk assessment lacks the ability to predict which subgroup will gain benefit from chemotherapy [5].

One possible reason for the observed clinical heterogeneity in this group is differences in the antitumour immune response. The tumour-draining lymph nodes (TDLNs) may be particularly relevant considering they serve either as effective barriers to tumour cell spread or as facilitators of dissemination of the primary tumour [6]. Uninvolved TDLNs function by allowing the expansion, differentiation and release of $\mathrm{B}$ and $\mathrm{T}$ cells by concentrating infiltrating tumour-associated antigens (TAAs) through their organised compartments including B cell follicles, germinal centres (GCs) and mantle zones [7]. Therefore, considering uninvolved TDLNs are the primary site for tumour antigen presentation and T cell/B cell activation [8], it is likely the type and extent of the TDLN-mediated immune response is important in tumour evolution in these patients. Despite this, histomorphological changes in TDLNs and their association with other clinicopathological risk factors have been poorly investigated in patients with stage II CRC. 
bioRxiv preprint doi: https://doi.org/10.1101/2020.04 21.054205; this version posted April 23, 2020. The copyright holder for this preprint

(which was not certified by peer review) is the author/funder, who has granted bioRxiv a license to display the preprint in perpetuity. It is made available under aCC-BY-NC-ND 4.0 International license.

Recently, there has been increasing interest in immunomodulatory microRNAs (miRNA) in tumour tissue. The expression of miRNA-21 (miR-21), which is arguably the most dysregulated miRNA in stage II tumours [9], functions to reduce the antigen-presenting capabilities of dendritic cells and suppresses anti-tumour T-cells in the tumour microenvironment (TME) [10-13]. Further, elevated miR-21 has been inversely associated with specific T cell populations within CRC [14] and has prognostic value in stage II [9, 15-16]. Beyond the TME however, little is known about the distal effects of miR-21, even though tumourigenic T cell responses influence TDLN B-cell compartments [17] and miR-21 is known to travel within tumour-derived extracellular vesicles to more distal sites in the body $[18,19]$. Taken together, the immunomodulatory effects of tumour markers such as miR-21 could be reflected in the histomorphology of TDLNs. Currently, little is known about the TDLN response with tumours that show high expression of miR-21.

The aim of this pilot study was to begin to characterise TDLN histomorphological features with tumour pathological risk factors including miR-21 in a small cohort of stage II CRC. 


\section{MATERIALS AND METHODS}

\section{Cohort}

All participants in this study underwent surgery with curative intent at our institution between March 2017 and October 2018. Inclusion criteria were stage II adenocarcinomas of the colon or rectum where disease stage was defined according to the $8^{\text {th }}$ Edition AJCC TNM staging system [20]. People with a history of malignancy, inflammatory bowel disease or those undergoing neo-adjuvant therapy were excluded prior to the analysis. A total of 23 patients were eligible for inclusion and all provided written informed consent. This study was conducted in accordance with the Declaration of Helsinki and ethical approval was approved by the Health \& Disabilities Ethics Committee, New Zealand (15/CEN/143; 18/CEN/138).

Demographic and clinicopathological data was extracted from hospital records and stored deidentified on a secured database (REDCap). The clinicopathological data included tumour T stage, cell type, grade, lymphovascular invasion, peri-neural invasion, multiple polyps, number of TDLN excised, pre-operative carcinoembryonic antigen (CEA) levels and deficiency in mismatch repair (dMMR) proteins. Patients with dMMR tumours had no positive immunohistochemical staining of at least one of the following MMR proteins; MLH1, MSH2, MSH6 and PMS2. High/low CEA was determined by a $3.5 \mu \mathrm{g} / \mathrm{L}$ cut-off value (private communication). All of the following assays were performed blinded to patient demographic and clinicopathological data. 
bioRxiv preprint doi: https://doi.org/10.1101/2020.04 21.054205; this version posted April 23, 2020. The copyright holder for this preprint (which was not certified by peer review) is the author/funder, who has granted bioRxiv a license to display the preprint in perpetuity. It is made available under aCC-BY-NC-ND 4.0 International license.

\section{H\&E staining Lymph Nodes}

Formalin fixed paraffin embedded (FFPE) lymph blocks were obtained from the Department of Pathology following routine histopathological assessment. FFPE samples were then placed in premade tissue microarray (TMA) blocks (Unitma) as $3 \mathrm{~mm}$ diameter cores using a Manual Tissue Microarrayer (Quick-Ray ${ }^{\mathrm{TM}}$ ). Representative areas from the donor blocks were chosen based on the density of tissue and embedded in TMA recipient blocks. Sections of $3 \mu \mathrm{m}$ were cut in triplicate on a microtome (Sakura Tissue Tek) and transferred to adhesive-coated slides. Triplicate sections were air dried and incubated at $60^{\circ} \mathrm{C}$ for 60 minutes. Sections were dewaxed with xylene, rehydrated with graded alcohol washes, and stained with Haematoxylin and eosin (H\&E).

\section{Histomorphological Analysis of Lymph Nodes}

The following evaluation procedure was based on a previous methodology by Seidl et al [7]. Morphometrical analysis was performed on 4 x (field of view) H\&E TDLN images (Figure 1). All TDLN compartments were annotated using ImageJ software [21]. Specifically, GCs and B-cell follicles (characterised by an intense blue ring around GCs) were quantified (Figure 1). Follicle and GC density were calculated as the average number of follicles/GCs per lymph node ( $\mathrm{f} / \mathrm{n}$ and GC/n) and follicle and GC size were calculated by averaging the circumference of the 3 largest follicles/GCs in each lymph node. Lastly, the mantle zone was calculated as the average follicle area minus the average GC area. Triplicate sections were analysed individually and averaged. 


\section{Annotations}

\section{Calculations}

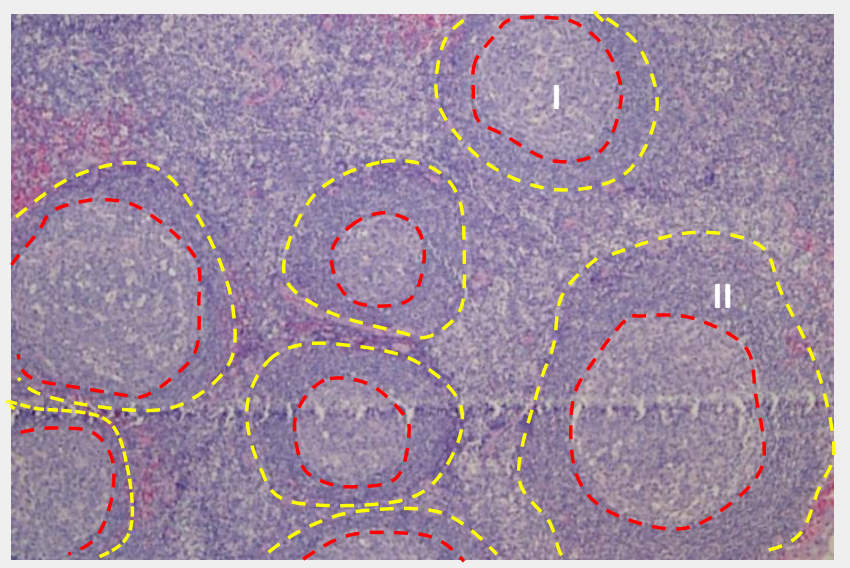

$\mathbf{I}=$ Germinal Centre within B-cell follicle

II = Mantle zone

Follicle and GC density = average \# of follicles/GCs per node (f/n and $\mathrm{gc} / \mathrm{n})$

Follicle and GC size $=$ average circumference of the 3 largest follicles/GCs per node $\left(\mathrm{mm}^{2}\right)$

Mantle zone $=$ average follicle area - average GC area

FIGURE 1: Evaluation procedure for TDLN histomorphological analysis. Evaluation is modified

from a previously published method (7). Left: All lymph nodes were annotated for B cell

compartments (red and yellow dashed lines) using ImageJ. (I) Circular Germinal centre (GCs) within

B-cell follicle, (II) Mantle zone. Right: Calculations for follicle and GC density, follicle and GC size, and mantle zone.

\section{Tumour miR-21 analysis}

Tumour and adjacent normal mucosa specimens were resected as fresh tissue at the time of surgery.

Surgical samples were available for 20 patients in the cohort. Samples were split in two for storage in RNAlater (Life Technologies) or formalin at 4. Formalin fixed tissues were embedded in paraffin, sectioned and stained with $H \& E$. A pathologist confirmed the H\&E slides of abnormal tissue as tumour and determined the tumour cell percentage. A pathologist also confirmed there were no tumour cells within normal tissue. One participant was excluded from the analysis where the abnormal sample could not be confirmed as malignant.

RNA was extracted from the tissue stored in RNAlater using the miRNeasy kit (Qiagen) following the manufacturer's protocol. Total RNA quantity and quality was validated using the Nanodrop spectrophotometer and $10 \mathrm{ng}$ of total RNA was used to synthesise cDNA using the TaqMan Advanced miRNA cDNA Synthesis Kit (Applied Biosystems). miRNA expression of hsa-miR-21-5p, 
bioRxiv preprint doi: https://doi.org/10.1101/2020.04 21.054205; this version posted April 23, 2020. The copyright holder for this preprint

(which was not certified by peer review) is the author/funder, who has granted bioRxiv a license to display the preprint in perpetuity. It is made available under aCC-BY-NC-ND 4.0 International license.

hsa-miR-345-5p and hsa-miR-16-5p was examined by real-time PCR using the TaqMan ${ }^{\mathrm{TM}}$ Fast Advanced Master Mix, specific miRNA assays (Applied Biosystems) and the RotorGene 6000 detection system. The geometric mean of the two housekeeper genes (miR-345 and miR-16) were used to normalise miR-21 average $C_{t}$ values. The fold change for each sample was calculated using the $2^{-\Delta \Delta \mathrm{Ct}}$ method $^{22}$ based on a comparison between matched tumour and normal mucosa. A fold change of $\geq 2$ was considered overexpression of miR-21.

\section{Statistical Analysis}

All statistical analysis was performed using GraphPad Prism software (GraphPad Prism 7.00

software, Inc.). For categorical variables differences were tested using Fisher's exact tests.

Correlations between continuous variables were tested using Spearman Rank correlation. Normally distributed continuous variables were reported as mean \pm standard deviation and differences were tested using unpaired t-tests. Non-normally distributed continuous variables were reported as median (interquartile range) and differences were tested using Mann-Whitney U-tests. A significance level of $5 \%$ was chosen. 
bioRxiv preprint doi: https://doi.org/10.1101/2020.04 21.054205; this version posted April 23, 2020. The copyright holder for this preprint (which was not certified by peer review) is the author/funder, who has granted bioRxiv a license to display the preprint in perpetuity. It is made available under aCC-BY-NC-ND 4.0 International license.

\section{RESULTS}

\section{Cohort demographics and characteristics}

A total of 23 participants were included in the analysis. Tumour samples were available for 20 out of 23 participants and TDLNs were available for 21 out of 23 participants. Of the entire cohort, the mean age was 65 years (range 34 to 80 years), and 15 participants were female (65\%). Other cohort demographics and tumour characteristics are shown in Table 1. Participant demographic and tumour characteristics stratified by miR-21 and lymph node morphology status are available in supplementary Tables $1 \& 2$. 
bioRxiv preprint doi: https://doi.org/10.1101/2020.04.21.054205; this version posted April 23, 2020. The copyright holder for this preprint (which was not certified by peer review) is the author/funder, who has granted bioRxiv a license to display the preprint in perpetuity. It is made available under aCC-BY-NC-ND 4.0 International license.

TABLE 1: Cohort demographics and tumour clinicopathological characteristics

\begin{tabular}{|c|c|c|c|}
\hline & & $\mathbf{N}(\%)$ & Mean +/- SD (range) \\
\hline \multirow{2}{*}{ Gender } & Male & $8(35)$ & \\
\hline & Female & $15(65)$ & \\
\hline \multirow{4}{*}{ Ethnicity } & European & $19(83)$ & \\
\hline & Māori & $2(9)$ & \\
\hline & Pacific Island & $1(4)$ & \\
\hline & Asian & $1(4)$ & \\
\hline \multirow{3}{*}{ T stage } & T3 & $16(69)$ & \\
\hline & $\mathrm{T} 4 \mathrm{a}$ & $5(22)$ & \\
\hline & $\mathrm{T} 4 \mathrm{~b}$ & $2(9)$ & \\
\hline \multirow{2}{*}{ Histological type } & Adenocarcinoma & $19(83)$ & \\
\hline & Mucinous adenocarcinoma & $4(17)$ & \\
\hline \multirow{3}{*}{ Grade (differentiation) } & Well & $15(68)$ & \\
\hline & Moderately & $1(5)$ & \\
\hline & Poorly & $6(27)$ & \\
\hline \multirow{3}{*}{ CEA $^{\mathrm{a}}$} & $<3.5$ & $12(52)$ & $1.84 \pm 0.46(1.1-2.4)$ \\
\hline & & & $11.54 \pm 10.71$ \\
\hline & $\geq 3.5$ & $11(48)$ & $32.4)$ \\
\hline \multirow{2}{*}{$\begin{array}{l}\text { Extramural vascular } \\
\text { Invasion }\end{array}$} & Yes & $1(5)$ & \\
\hline & No & $22(95)$ & \\
\hline \multirow{2}{*}{ Peri-neural Invasion } & Yes & $1(5)$ & \\
\hline & No & $22(95)$ & \\
\hline \multirow{2}{*}{ Lymphatic Invasion } & Yes & $5(22)$ & \\
\hline & No & $18(78)$ & \\
\hline \multirow{2}{*}{ Multiple Polyps } & Yes & $10(46)$ & \\
\hline & No & $12(54)$ & \\
\hline \multirow{2}{*}{$\mathbf{d M M R}^{\mathrm{b}}$} & No evidence & $13(57)$ & \\
\hline & Evidence & $10(43)$ & \\
\hline \multirow{2}{*}{$\begin{array}{l}\text { TDLNs examined for } \\
\text { cancer }^{c}\end{array}$} & $\geq 12$ & $21(93)$ & $25(5-50)$ \\
\hline & $<12$ & $2(7)$ & \\
\hline $\begin{array}{l}\text { TDLNs examinable for } \\
\text { morphology patterns }\end{array}$ & & & $11 \pm 6(3-25)$ \\
\hline
\end{tabular}

${ }^{a}$ CEA level $3.5 \mu \mathrm{g} / \mathrm{L}$ cut-off (private communication).

${ }^{\mathrm{b} D e f i c i e n c y ~ i n ~ a t ~ l e a s t ~ o n e ~ o f ~ M S H 2, ~ M S H 6, ~ P M S 2, ~ M L H 1 . ~}$

$c<12$ resected lymph nodes is associated with a worse outcome [2]. 
bioRxiv preprint doi: https://doi.org/10.1101/2020.04 21.054205; this version posted April 23, 2020. The copyright holder for this preprint (which was not certified by peer review) is the author/funder, who has granted bioRxiv a license to display the preprint in perpetuity. It is made available under aCC-BY-NC-ND 4.0 International license.

\section{Histomorphology of TDLNs}

All TDLNs excised from surgical specimens in the 21 participants with stage II CRC were collected. TDLNs were excluded from the analysis if less than $50 \%$ of lymph node tissue was present inside the $3 \mathrm{~mm}$ cores. A total of 251 lymph node cores were examined for morphology patterns. For 13 participants at least 10 lymph nodes were examined while the remainder had between 3-9 lymph nodes examinable.

Histomorphological patterns were stratified by clinicopathological features (sup. Table 2). Follicle density was significantly higher in patients with T3 tumours (14 $\pm 3 \mathrm{f} / \mathrm{n})$ compared to patients with T4a/b tumours $(11 \pm 3 \mathrm{f} / \mathrm{n}, p=0.03$; Figure $2 \mathrm{~A})$. A statistical trend was seen between dMMR tumours and GC density, where patients with dMMR tumours had a higher GC density (10 $\pm 4 \mathrm{gc} / \mathrm{n})$ compared to patients without $(8 \pm 3 \mathrm{gc} / \mathrm{n} ; p=0.063$; Figure $2 \mathrm{~B})$. For follicle size, patients without lymphatic invasion had a greater spread of data with a larger Interquartile range compared to patients with lymphatic invasion (0.093-0.210 vs 0.082-0.133; Figure 2C). The same was true for GC size (0.0310.045 vs 0.031-0.100; Figure 2D). However, there was no statistical difference between the median follicle or GC size and patients with and without lymphatic invasion. Lastly, patients with high CEA levels ( $\geq 3.5 \mathrm{ng} / \mathrm{ml}$ ) had a significantly higher GC density (10 $\pm 3 \mathrm{gc} / \mathrm{n})$ compared to patients with low levels $(8 \pm 3 \mathrm{gc} / \mathrm{n} ; p=0.04$; Figure $2 \mathrm{E})$. No other associations were detected between these TDLN morphology patterns and clinicopathological features (sup. Table 2). 
A

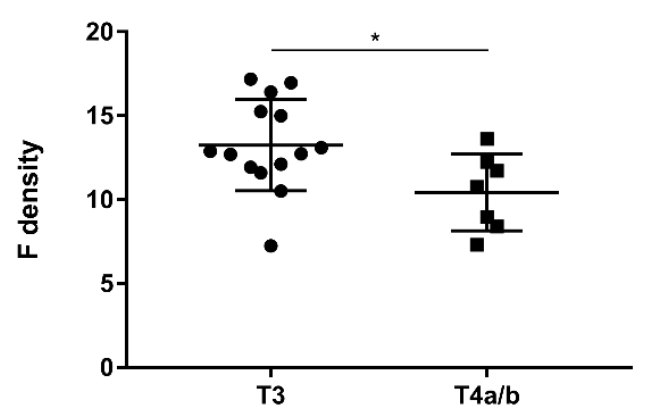

C



$\mathbf{E}$

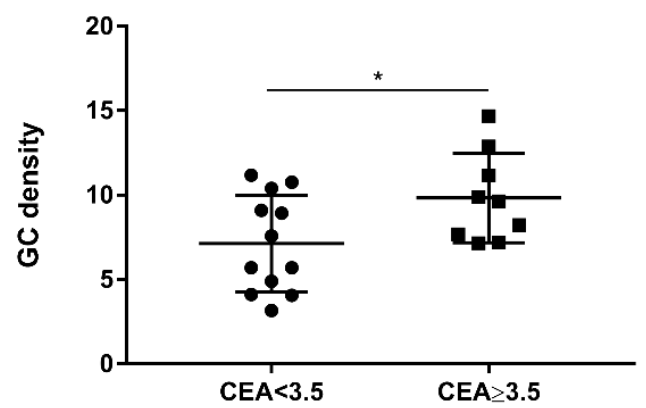

B

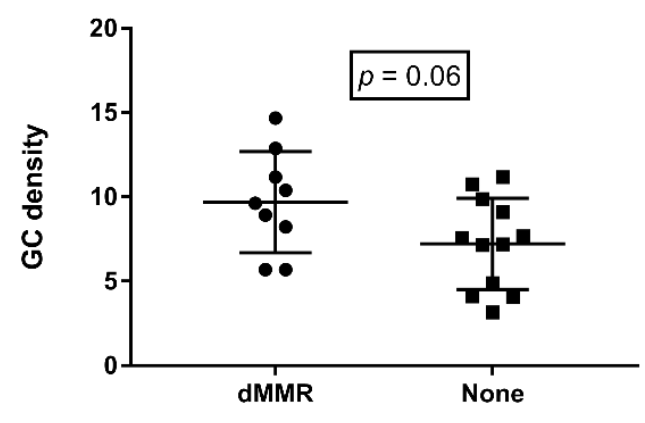

D

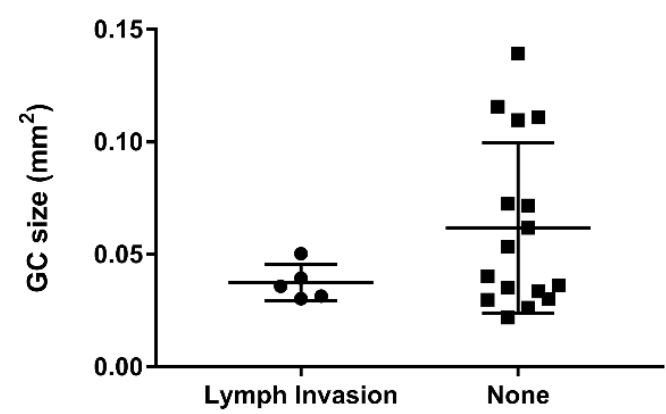

FIGURE 2: TDLN histomorphology and clinicopathological features. A) B-cell follicle density in T3 versus T4a/b tumours. B) GC density in dMMR versus proficient MMR tumours. $C$-D) B-cell follicle and GC size in tumours with lymphatic invasion versus those without. E) GC density in patients with serum $C E A<3.5 \mathrm{ng} / \mathrm{mL}$ versus serum $C E A \geq 3.5 \mathrm{ng} / \mathrm{ml} . \mathrm{f} / \mathrm{n}=$ follicles per node, $\mathrm{gc} / \mathrm{n}=$ germinal centres per node. *p $<0.05$, Student's $t$-test. 
bioRxiv preprint doi: https://doi.org/10.1101/2020.04 21.054205; this version posted April 23, 2020. The copyright holder for this preprint

(which was not certified by peer review) is the author/funder, who has granted bioRxiv a license to display the preprint in perpetuity. It is made available under aCC-BY-NC-ND 4.0 International license.

\section{Tumour miR-21 and TDLN histomorphology}

miR-21 expression in CRC tumour tissue and matched adjacent normal mucosa were compared in 19 out of 20 available samples. One sample was excluded from the analysis where abnormal tissue could not be confirmed as malignant. miR-21 tumour levels were 2-fold higher compared to normal mucosa (1.02 (0.89-1.1) vs $2.08(1.1-2.8) p=0.0008$; Figure 3A). In a comparison between tumour cell percentage and miR-21 tumour fold change, no correlation was detected $\left(r^{2}=0.094, p=0.20\right.$; sup. Figure 1).

To understand whether miR-21 tumour levels were associated with histomorphological changes in TDLNs, high miR-21 expressing tumours were compared to low expressing tumours for TDLN histomorphological characteristics (sup. Table 2). A total of 17 out of 23 patients had both tumour miR-21 levels and TDLN morphology measures available for comparison. Patients with tumour miR21 levels $<2$ fold change had a significantly higher median follicle size $\left(0.150 \mathrm{~mm}^{2}(0.132-0.230) \mathrm{vs}\right.$ $\left.0.094 \mathrm{~mm}^{2}(0.091-0.102) ; p=0.03\right)$, GC size $\left(0.062 \mathrm{~mm}^{2}(0.045-0.110)\right.$ vs $0.033 \mathrm{~mm}^{2}(0.027-0.039) ; p$ $=0.01)$ and Marginal zone $\left(0.090 \mathrm{~mm}^{2}(0.086-0.120)\right.$ vs $\left.0.064 \mathrm{~mm}^{2}(0.058-0.070) ; p=0.01\right)$ compared to patients with miR-21 levels $\geq 2$ fold change (Figure 3B-D). No other statistically significant associations were found (sup. Table 2). 
A

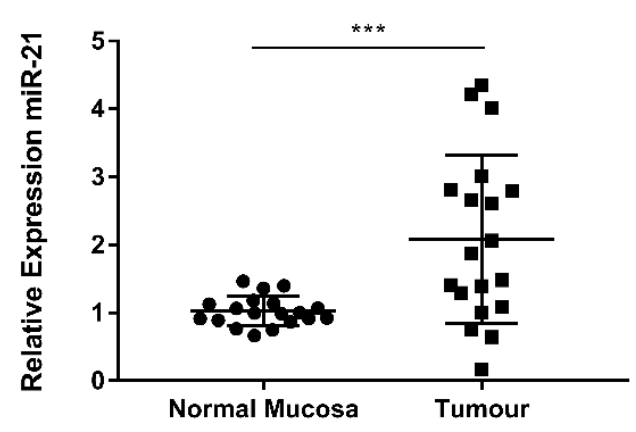

C



B

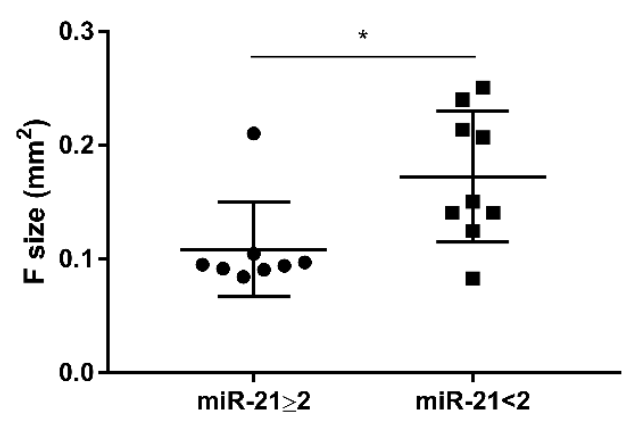

D



FIGURE 3: TDLN histomorphology and miR-21 tumour levels. A) Relative expression of miR-21 in matched tumour and normal mucosa. B-D) B-cell follicle size, GC size and marginal zone in patients with tumour miR-21 $\geq 2$ fold change compared to patients with tumour mi-21 $<2$ fold change. ${ }^{* * *} p<$ 0.001, ${ }^{*} p<0.05$, Student's t-test, Mann-Whitney U-test. 


\section{DISCUSSION}

This study is the first to observe associations between TDLN histomorphological features and tumour miR-21 levels in participants with stage II CRC. The key findings include: 1) Tumour T stage and serum CEA levels were associated with follicle density and GC density, respectively: 2) Trends between dMMR tumours, lymphatic invasion and TDLN features were detected: 3) Elevated tumour miR-21 was associated with decreased follicle, GC size and marginal zone.

Variation in the number and size of B cell primary follicles and GCs in TDLNs could be reflective of a cancer-specific immune response and therefore provide prognostic information. These spatially organised compartments, along with $\mathrm{T}$ cell zones respond to the local tumour-associated immune signature within the draining lymph fluid [23]. Specifically, the immunomodulation effects of B cell follicles and GCs change the composition of B memory and plasma cell populations that home back to the site of the tumour [17]. While the effect of infiltrating immune cell populations is mostly focused on T cells, evidence is beginning to emerge for the role of infiltrating B cells [17]. Furthermore, with a clinically feasible approach in mind, B cell compartments are the most recognisable features that can be accurately quantified within TDLNs H\&E slides; a process that could be automated in the future.

Our data suggest there is a potential link between TDLN histomorphological features and known tumour pathological risk factors. It is plausible that having a greater follicle or GC density and size generates a stronger anti-tumour immune response. For example, dMMR tumours are known to be more immunogenic, characterised by an abundance of tumour infiltrating lymphocytes in response to MSI-induced frameshift peptides [24]. Our data indicate dMMR participants had a trend towards greater GC density, although this did not reach significance. Conversely, elevated tumour miR-21 is known to suppress the anti-tumour immune response in the TME and clinical studies suggest elevated miR-21 is associated with a poorer overall survival [9-16]. We show that elevated miR-21 is also 
associated with smaller average follicle and GC size. While we have not shown any prognostic potential of the TDLNs, considering the various links to tumour pathological factors, this area is worth further investigation.

While no other groups have examined TDLN histomorphological features as biomarkers in CRC before, there have been insights into the TDLNs of patients with breast and oral cancer. Seidl et al. have reported that patients with stage I-III breast cancer, those with more aggressive and higher-risk breast cancer types had a significantly higher follicle and GC density [7]. Conversely, Vered et al. found in a cohort of stage I-III oral cancer, a higher percentage of TDLN follicles was associated with a significantly better prognosis [25]. The discrepancies in these studies and the overall lack of research in this area make it difficult to determine whether follicle density actually reflects an anti-tumour response and how prognostic this is. Further, there is currently no consensus for quantifying TDLN histomorphological features and their prognostic value could be cancer type specific.

Limitations of the study include the lack of assessment of the prognostic ability of TDLNs in stage II CRC due to a small sample size and insufficient follow-up time. This area of biomarker research is still well within the discovery phase and mechanistic studies are required to further elucidate the link between follicle, GC density and an anti-tumour response. This may further inform the approach to quantifying TDLN histomorphological changes which is currently not standardised.

\section{CONCLUSION}

In conclusion, we are the first to explore TDLNs histomorphological changes in patients with stage II CRC and their associations with tumour pathological factors. We suggest that the histomorphological variation could be reflective of cancer-specific host immune responses. 
bioRxiv preprint doi: https://doi.org/10.1101/2020.04 21.054205; this version posted April 23, 2020. The copyright holder for this preprint (which was not certified by peer review) is the author/funder, who has granted bioRxiv a license to display the preprint in perpetuity. It is made available under aCC-BY-NC-ND 4.0 International license.

\section{REFERENCES}

1. Cancer burden rises to 18.1 million new cases and 9.6 million cancer deaths in 2018. Latest global cancer data: International Agency for Research on Cancer, World Health Organization. 12 September 2018: https://www.who.int/cancer/PRGlobocanFinal.pdf. Accessed 30 November 2018.

2. NCCN Clinical Practice Guidelines in Oncology Colon Cancer 2.2018: National Comprehensive Cancer Network. Available at https://www.nccn.org/professionals/physician_gls/pdf/colon.pdf. Accessed 30 November 2018.

3. Casadaban L, Rauscher G, Aklilu M, Villenes D, Freels S, Maker AV. Adjuvant Chemotherapy Is Associated With Improved Survival in Patients With Stage II Colon Cancer. Cancer. 2016;122(21):3277-87.

4. O'Connor E, Greenblatt D, LoConte N, Gangnon R, Liou J, Heise C, et al. Adjuvant chemotherapy for stage II colon cancer with poor prognostic features. Journal of Clinical Oncology. 2011; 29(25):3381-8.

5. Benson AB, Hamilton SR. Path Toward Prognostication and Prediction: An Evolving Matrix. Journal of Clinical Oncology. 2011;29(35):4599-601.

6. Ferris RL, Lotze MT, Leong SPL, Hoon DSB, Morton DL. Lymphatics, lymph nodes and the immune system: barriers and gateways for cancer spread. Clinical \& Experimental Metastasis. 2012;29(7):729-36.

7. Seidl M, Bader M, Vaihinger A, Wellner UF, Todorova R, Herde B, et al. Morphology of Immunomodulation in Breast Cancer Tumor Draining Lymph Nodes Depends on Stage and Intrinsic Subtype. Scientific Reports. 2018;8.

8. Chandrasekaran S, King MR. Microenvironment of Tumor-Draining Lymph Nodes: Opportunities for Liposome-Based Targeted Therapy. International Journal of Molecular Sciences. 2014;15(11):20209-39. 
9. Schetter AJ, Leung SY, Sohn JJ, Zanetti KA, Bowman ED, Yanaihara N, et al. MicroRNA expression profiles associated with prognosis and therapeutic outcome in colon adenocarcinoma. Jama-Journal of the American Medical Association. 2008;299(4):425-36

10. Lu L, Byrnes K, Han C, Wang Y, Wu T. miR-21 Targets 15-PGDH and Promotes Cholangiocarcinoma Growth. Molecular Cancer Research. 2014;12(6):890-900.

11. Merline R, Moreth K, Beckmann J, Nastase MV, Zeng-Brouwers J, Tralhao JG, et al. Signaling by the Matrix Proteoglycan Decorin Controls Inflammation and Cancer Through PDCD4 and MicroRNA-21. Science Signaling. 2011;4(199).

12. Mima K, Nishihara R, Nowak JA, Kim SA, Song MY, Inamura K, et al. MicroRNA MIR21 and T Cells in Colorectal Cancer. Cancer Immunology Research. 2016;4(1):33-40.

13. Sheedy FJ, Palsson-McDermott E, Hennessy EJ, Martin C, O'Leary JJ, Ruan QG, et al. Negative regulation of TLR4 via targeting of the proinflammatory tumor suppressor PDCD4 by the microRNA miR-21. Nature Immunology. 2010;11(2):141-U59.

14. Mima K, Nishihara R, Nowak JA, Kim SA, Song MY, Inamura K, et al. MicroRNA MIR21 and T Cells in Colorectal Cancer. Cancer Immunology Research. 2016;4(1):33-40.

15. Shibuya H, Iinuma H, Shimada R, Horiuchi A, Watanabe T. Clinicopathological and Prognostic Value of MicroRNA-21 and MicroRNA-155 in Colorectal Cancer. Oncology. 2010;79(3-4):313-20.

16. ka Y, Takahashi M, Hur K, Nagasaka T, Tanaka K, Inoue Y, et al. Serum miR-21 as a Diagnostic and Prognostic Biomarker in Colorectal Cancer. Jnci-Journal of the National Cancer Institute. 2013;105(12):849-59.

17. Linnebacher M, Maletzki C. Tumor-infiltrating B cells The ignored players in tumor immunology. Oncoimmunology. 2012;1(7):1186-8.

18. El Andaloussi S, Maeger I, Breakefield XO, Wood MJA. Extracellular vesicles: biology and emerging therapeutic opportunities. Nature Reviews Drug Discovery. 2013;12(5):348-58.

19. Tsukamoto M, Iinuma H, Yagi T, Matsuda K, Hashiguchi Y. Circulating Exosomal MicroRNA-21 as a Biomarker in Each Tumor Stage of Colorectal Cancer. Oncology. 2017;92(6):360-70. 
bioRxiv preprint doi: https://doi org/10.1101/2020.0421.054205; this version posted April 23, 2020. The copyright holder for this preprint (which was not certified by peer review) is the author/funder, who has granted bioRxiv a license to display the preprint in perpetuity. It is made available under aCC-BY-NC-ND 4.0 International license.

20. Weiser MR. AJCC 8th Edition: Colorectal Cancer. Annals of surgical oncology. 2018 Jun $1 ; 25(6): 1454-5$.

21. Schneider, C. A.; Rasband, W. S. \& Eliceiri, K. W. NIH Image to ImageJ: 25 years of image analysis. Nature methods. 2018: 9(7): 671-675, PMID 22930834.

22. Livak KJ, Schmittgen TD. Analysis of relative gene expression data using real-time quantitative PCR and the 2(T)(-Delta Delta C) method. Methods. 2001;25(4):402-8.

23. Allen CDC, Okada T, Cyster JG. Germinal-center organization and cellular dynamics. Immunity. 2007;27(2):190-202.

24. Schwitalle Y, Kloor M, Eiermann S, Linnebacher M, Kienle P, Knaebel HP, et al. Immune response against frameshift-induced neopeptides in HNPCC patients and healthy HNPCC mutation carriers. Gastroenterology. 2008;134(4):988-97.

25. Vered M, Schiby G, Schnaiderman-Shapiro A, Novikov I, Bello IO, Salo T, et al. Key architectural changes in tumor-negative lymph nodes from metastatic-free oral cancer patients are valuable prognostic factors. Clinical \& Experimental Metastasis. 2014;31(3):327-38. 